\title{
Worries, Mental and Emotional Health Difficulties of Portuguese University Students
}

\author{
Marta Reis \\ Researcher at \\ FMH/Universidade de Lisboa | Estrada da Costa 1495-688 Cruz Quebrada | PORTUGAL \\ Faculdade de Motricidade Humana/Universidade de Lisboa, Portugal \\ ISAMB/Faculdade de Medicina, Universidade de Lisboa, Portugal \\ Lúcia Ramiro \\ Faculdade de Motricidade Humana/Universidade de Lisboa, Portugal \\ ISAMB/Faculdade de Medicina, Universidade de Lisboa, Portugal \\ Margarida Gaspar de Matos \\ Faculdade de Motricidade Humana/Universidade de Lisboa, Portugal \\ ISAMB/Faculdade de Medicina, Universidade de Lisboa, Portugal
}

\begin{abstract}
The aim of this study was to reach an in-depth understanding on how Portuguese university students feel towards life in general, which are their worries, how often they feel worried, and how intense their worries are. Moreover, it was intended to identify the kind of psychosocial variables involved, strategies they use as well as which are the sources of their well-being. A total of 2991 university students, participated in the quantitative study and in the qualitative study, there were 50 participants between 18 and 35 years old. A significant minority of students got worried frequently, allowing their worries to interfere significantly in their lives. Gender and age differences were found. Having worries demonstrated to be relevant and negatively associated with young people's perception of well-being, self-regulation and resilience; showing that the mental health of the Portuguese university students is at risk, mainly when their social emotional skills are underdeveloped.
\end{abstract}

Key-words: Worries, Mental health, Well-being, Self-regulation; Resilience; University students; Portugal

\section{INTRODUCTION}

Worry is a primary cognitive characteristic of anxiety, and it has been characterised by the repeated experience of thoughts about potential negative events. The content of the worry is typically related to future events whose outcomes besides uncertain, have one or more possible negative outcomes ${ }^{[1]}$.

Chronic, excessive and uncontrollable worry about multiple topics is the main defining feature of Generalized Anxiety Disorder (GAD; Diagnostic and statistical manual of mental disorders: DSM-5 $5^{\text {th }}$ Edition), often causing severe incapacity. In addition to excessive and uncontrollable worry, a diagnosis of GAD requires at least three other associated symptoms (e.g., concentration problems, sleeping difficulties, fatigue). However, given that excessive, uncontrollable worry is the central requirement for a diagnosis of GAD, it was the focus of the current study[2]. 
The question remains of why individuals prone to worry find it so difficult to disengage from their worry once it begins. Although anticipation of probable danger is adaptive, it is unclear why excessive worry persists when it often causes distress and has few apparent benefits. Many studies have demonstrated that the phenomenology of worry consists largely of verbal thought. For example, Stokes, \& Hirsch ${ }^{[3]}$ demonstrated that both individuals with GAD and non-worriers reported a predominance of verbal thought during a period of worry, compared to a period of relaxation in which participants with GAD reported near equal amounts of imagery and verbal thought, and non-worriers reported a predominance of imagery. This is also reported in other studies that found that worry is experienced primarily as verbal thought, in contrast to trauma recall which is experienced primarily in images $[4,5]$.

Recently a few authors have begun to address and study worry as being independent from anxiety and concern. Anxiety refers to an emotion characterized by tension, worries and physical responses such as increased blood pressure. Therefore, worries are not to be confused with anxiety since they are limited to negative thoughts and images and at most they represent a part of anxiety. In addition, worries are more specific and intrusive than mere "concerns", which may have no relevant consequence in behaviour [6-8]. Although worries are overall subclinical symptoms, they can affect well-being and mental health when they become too frequent or too intense in daily life, thus contributing to an unhealthy degree of anxiety.

Although anxiety also appears as a common, functional, and transitory experience, its frequency and intensity can vary to a large extent, depending on the individuals' period of development. In this sense, it allows adolescents to engage in new, unexpected, or even dangerous situations [9]. One of the factors that seems to have a great effect on the anxiety levels of young people is their worries, particularly their number and intensity.

Youth with high levels of anxiety often report high levels of worries and more negative beliefs associated to them. In particular, intensity of worry was the variable that seemed to differentiate a non-clinically referred adolescent from a clinically referred one [10]. Therefore, an understanding of adolescent worries can provide pivotal information on their lifestyles, problems, and interests, thus increasing attention to the content and correlates of adolescent worries in terms of health education and well-being ${ }^{[6,7] .}$

Our research also stressed that there is a lack of inclusion of young people's own perspectives regarding their perceived emotional states, current worries, what really matters to them, and their input for increasing their own well-being ${ }^{[6,11]}$. Besides, most of the studies reviewed were based in quantitative approaches, surveys and self-reported questionnaires ${ }^{[6,12-14]}$, targeted clinical populations or population studies designed for other public health monitoring aims, and not specifically aiming to understanding worries and solutions and the perception of wellbeing from children and adolescents' perspectives.

Considering the lack of studies about mental health in university students in Portugal, and attempting to capture the dynamic relations between youths and their context and taking into account the importance of having more knowledge on country-specificities, the aim of this study was to reach an in depth understanding about how Portuguese university students feel towards life in general, which are their worries, how often they feel worried, and how intense their worries are. Moreover, it is intended to find what kind of psychosocial variables (Selfregulation, Resilience, Anxiety and Perceived school performance) are associated to worries and what kind of strategies university students use as well as which are their sources of wellbeing. This will be analyzed and compared in two studies. 


\section{MATERIALS AND METHODS}

\section{Participants and Procedure}

The national HBSC/JUnP study is an extension of two investigations conducted by the Social Adventure team - HBSC (Health Behavior in school aged children; http://aventurasocial.com/verartigo.php?article $\mathrm{id}=238$ ) and HBSC/SSREU (Sexual and Reproductive Health of university students; http://aventurasocial.com/verartigo.php?article id=98). The HBSC/JUnP followed all the rules for research outlined in 2008 by the World Medical Association Declaration of Helsinki, and was approved by the Ethics Commission of the Medicine Academic Center of Lisbon of the Faculty of Medicine, University of Lisbon.

In the quantitative study, a total of 2991 youths ( $n=2203 ; 73.7 \%$ women), aged from 18 to 35 years old (22.43 \pm 3.83$)$ participated in the study. In the qualitative study, a total of 50 youths ( $n=38 ; 76 \%$ women), aged from 18 to 35 years old participated in the study.

Data collection was performed using an online survey and the Limesurvey platform (quantitative study) and focal groups (qualitative study). Prior to data collection, the purpose of the study was informed to youths and informed consents were obtained. Confidentiality of the responses to the questionnaire and during the data process was assured to students.

\section{Measures and Instruments}

For the purpose of this study the following variables were selected: Life satisfaction, relation with family and friends (evaluated on a scale from 0 to 10 where the higher value corresponds to higher life satisfaction and better relation); How (happy) they feel towards life; Frequency of worries; Intensity of worrying in daily life; and psychosocial variables such as ResilienceRES[15-17], Self-regulation-SR [18,19], Anxiety-STAI-T [20,21], Buss \& Perry[22,23], Boredom with university and academic performance ${ }^{[24]}$.

\section{Data analysis}

Data from Limesurvey was transferred to an electronic data file. All variables were checked for data inaccuracy by running SPSS frequencies, and afterwards, an analysis on missing values was conducted. All data were tested for normality prior to any analyses using KolmogorovSmirnov tests, as well as Levene's test for the homogeneity of variance. Both descriptive and inferential statistics were applied. All statistical analyses were completed using the SPSS 24.0 (Statistical Package for Social Sciences) and the significance level was set at $\mathrm{p}<0.05$.

\section{RESULTS}

As previously mentioned, the main objective of this study was to understand in depth how university students perceived their life satisfaction, which were their worries, and their contingencies. Moreover, we wanted to know which psychosocial variables and strategies they used to cope with their worries and how they perceived their life satisfaction and well-being.

Feelings about life, frequency and intensity of worries and self-regulation, and resilience The great majority of university students reported a good life satisfaction average (M=6.99; $\mathrm{SD}=1.91)$ and feeling happy or very happy (73.8\%) about life.

As for frequency of worries, only $8.2 \%$ of university students mentioned almost never worrying, worrying seemed to be a real issue in students, with $36.4 \%$ of young people mentioned being worried several times a week; $27.6 \%$ reported being worried several times a month; 18.9\% mentioned being worried almost every day, and 8.8\% reported being worried several times a day. As regards to intensity of worries, although the great majority (49.9\%) are 
worried and to be a problem that bothers them, they continue to live their lives. However, $12.1 \%$ of young people mentioned being worried in such an intense way that they cannot think or do anything else (see, table 1 ).

Regarding gender differences, women reported more frequently being worried several times a day (men: 5.6\%, women: 10.0\%), and several times a week (men: 33.2\%, women: 37.6\%), while men more frequently reported almost never worrying (men: 12.8\%, women: 6.6\%).

When analyzing the intensity of worries according to genders, men more frequently reported never worrying about anything at all (men: 4.7\%, women: $2.5 \%$ ), or having worries but not allowing them to interfere with the rest of their lives (men: 39.6\%, women: 33.3\%); and women more frequently reported being so intensively worried that they could not think about anything else (men: 8.4\%, women: 13.4\%) (see, table 1).

Self-regulation and resilience regarding worries prevention: the distribution of each item is shown in Table 1. The majority shows good levels of self-regulation and resilience. Nevertheless, two resilience subscales presented slightly lower mean values, namely the problem-solving subscale and the cooperation / communication scale.

The mean total score in relation to self-regulation was $143.94(\mathrm{SD}=16.68)$, with men showing significantly less self-regulation $(M=140.06, S D=18.02)$ than women $[(M=145.33, S D=18.73$ $(\mathrm{F}(1,2990)=46.716, \mathrm{p}=0.000)]$.

The mean total score in relation to resilience was $55.49(\mathrm{SD}=8.10)$, with men showing significantly less resilience $(\mathrm{M}=54.12, \mathrm{SD}=8.05)$ than women $[(\mathrm{M}=55.98, \mathrm{SD}=8.06(\mathrm{~F}(11$, $2990)=30.950, p=0.000)]$. And the means in relation to the subscales of resilience were 10.46 $(\mathrm{SD}=1.80)$ for objectives/ aspirations; $9.53(\mathrm{SD}=1.86)$ for self-awareness; $9.24(\mathrm{SD}=1.98)$ for self-efficacy; 9.17 ( $\mathrm{SD}=1.89$ ) for empathy; $8.76(\mathrm{SD}=1.83$ ) for cooperation/ communication; and $8.34(\mathrm{SD}=2.40)$ for problem solving. Regarding gender differences, men showed significantly less objectives/ aspirations $(M=10.23, S D=1.91)$; less self-awareness $(M=9.33$, $\mathrm{SD}=1.84)$; less empathy $(\mathrm{M}=8.64, \mathrm{SD}=1.90)$; less cooperation/ communication $(\mathrm{M}=8.64$, $\mathrm{SD}=1.90)$ and less problem solving $(\mathrm{M}=7.89, \mathrm{SD}=2.30)$; than women $[(\mathrm{M}=10.55, \mathrm{SD}=1.75(\mathrm{~F}$ $(1,2990)=17.987, \mathrm{p}=0.000) ; \mathrm{M}=9.60, \mathrm{SD}=1.87(\mathrm{~F}(1,2990)=11.969, \mathrm{p}=0.001) ; \mathrm{M}=9.29$, $\mathrm{SD}=1.88(\mathrm{~F}(1,2990)=33.070, \mathrm{p}=0.000) ; \mathrm{M}=8.80, \mathrm{SD}=1.81(\mathrm{~F}(1,2990)=4.093, \mathrm{p}=0.043) ; \mathrm{M}$ $=8.49, \mathrm{SD}=2.42(\mathrm{~F}(1,2990)=36.751, \mathrm{p}=0.000)]$. 
Table 1-Feelings about life, frequency and intensity of worries, self-regulation and resilience $(n=2991)$

\begin{tabular}{|c|c|c|c|c|c|c|c|}
\hline & \multicolumn{2}{|c|}{ Total } & \multicolumn{2}{|c|}{ Men } & \multicolumn{2}{|c|}{ Women } & \multirow[t]{2}{*}{$\boldsymbol{F}$} \\
\hline & $\mathbf{M}$ & SD & $\mathbf{M}$ & SD & $\mathbf{M}$ & SD & \\
\hline \multirow[t]{2}{*}{ Satisfaction with Life } & 6.99 & 1.91 & 6.95 & 1.83 & 7.00 & 1.93 & $.418^{\mathrm{n} . \mathrm{s}}$ \\
\hline & $\mathbf{N}$ & $\%$ & $\mathbf{N}$ & $\%$ & $\mathbf{N}$ & $\%$ & $\chi^{2}$ \\
\hline How do you feel about life (\%)? & & & & & & & $.021^{\mathrm{n} . \mathrm{s}}$ \\
\hline I feel happy/very happy & 2207 & 73.8 & 583 & 74.0 & 1624 & 73.7 & \\
\hline I don`t feel happy/ I feel unhappy & 784 & 26.2 & 205 & 26.1 & 579 & 26.3 & \\
\hline How often are you worried? (\%) & & & & & & & $44.605^{* * *}$ \\
\hline Several times a day & 264 & 8.8 & 44 & 5.6 & 220 & 10.0 & \\
\hline Almost every day & 564 & 18.9 & 148 & 18.8 & 416 & 18.9 & \\
\hline Several times a week & 1090 & 36.4 & 262 & 33.2 & 828 & 37.6 & \\
\hline Several times a month & 827 & 27.6 & 233 & 29.6 & 594 & 27.0 & \\
\hline Almost never & 246 & 8.2 & 101 & 12.8 & 145 & 6.6 & \\
\hline $\begin{array}{l}\text { How intense is worry in your } \\
\text { daily life (\%) }\end{array}$ & & & & & & & $29.818^{* * *}$ \\
\hline $\begin{array}{l}\text { So intense that it does not allow } \\
\text { me to think of anything else. }\end{array}$ & 362 & 12.1 & 66 & 8.4 & 296 & 13.4 & \\
\hline $\begin{array}{l}\text { It troubles me but it allows my life } \\
\text { to keep going. }\end{array}$ & 1492 & 49.9 & 373 & 47.3 & 1119 & 50.8 & \\
\hline $\begin{array}{l}\text { I have worries but I do not let them } \\
\text { interfere with my life }\end{array}$ & 1046 & 35.0 & 312 & 39.6 & 734 & 33.3 & \\
\hline \multirow[t]{2}{*}{ I worry about nothing at all } & 91 & 3.0 & 37 & 4.7 & 54 & 2.5 & \\
\hline & $\mathbf{M}$ & SD & $\mathbf{M}$ & SD & $\mathbf{M}$ & SD & $\boldsymbol{F}$ \\
\hline Self-regulation & 143.94 & 16.68 & 140.06 & 18.02 & 145.33 & 18.73 & $46.716^{* * *}$ \\
\hline Resilience - Total scale & 55.49 & 8.10 & 54.12 & 8.05 & 55.98 & 8.06 & $30.950^{* * *}$ \\
\hline Empathy - Resilience subscale & 9.17 & 1.89 & 8.84 & 1.90 & 9.29 & 1.88 & $33.070^{* * *}$ \\
\hline $\begin{array}{l}\text { Problem-solving - Resilience } \\
\text { subscale }\end{array}$ & 8.34 & 2.40 & 7.89 & 2.30 & 8.49 & 2.42 & $36.751^{* * *}$ \\
\hline Self-efficacy - Resilience subscale & 9.24 & 1.98 & 9.18 & 2.03 & 9.26 & 1.96 & $0.775^{\text {n.s }}$ \\
\hline $\begin{array}{l}\text { Cooperation/ communication - } \\
\text { Resilience subscale }\end{array}$ & 8.76 & 1.83 & 8.64 & 1.90 & 8.80 & 1.81 & $4.093^{*}$ \\
\hline $\begin{array}{l}\text { Self-awareness - Resilience } \\
\text { subscale }\end{array}$ & 9.53 & 1.86 & 9.33 & 1.84 & 9.60 & 1.87 & $11.969^{* * *}$ \\
\hline $\begin{array}{l}\text { Objectives/ aspirations - } \\
\text { Resilience subscale }\end{array}$ & 10.46 & 1.80 & 10.23 & 1,91 & 10.55 & 1.75 & $17.987^{* * *}$ \\
\hline
\end{tabular}

1 The total numbers differ considering that some participants have not replied to some variables.

${ }^{*} \mathrm{p}<.05 ;{ }^{* *} \mathrm{p}<.01 ;{ }^{* * *} \mathrm{p}<.001 ; \mathrm{n} . \mathrm{s}=$ not significant

In bold - values that correspond to an adjusted residual $\geq|1.9|$

\section{Current worries in university students}

The most frequent kind of worry reported was related to university (42\%) and included issues like university life, academic performance, and future expectations and life professional success. The second most frequent kind of worry was time management / organization of daily activities (38\%) and it included issues about academic, domestic and leisure activities such as practising sports, dancing/music, screen time, cooking, washing clothes, and having no free time. Issues related to economic/financial matters were the third most frequent kind of worry 
(22\%), including concerns about lack of money, parental unemployment, parental migration and extreme deprivation (no home or food). Family and related matters were the fourth most frequent kind of worry (16\%), including issues such as general family life and specific family problems, like diseases and deaths. Personal issues were the last referred worry (12\%) and included wellness and health, and un-wellness and potential health compromising behaviours.

\section{What makes university students feel well or help managing their worries}

Regarding what makes university students feel well or help managing their worries, physical exercise was the most frequent answer (38\%); listening to music, watching series/movies, and surfing the net were the second most reported (36\%); walking/ leaving home / going to the beach were the third most reported (24\%); and eating sweets and / or junk food, sleeping and staying still came in fourth $(20 \%)$ and fifth $(18 \%)$ place.

\section{Whom university students ask for support to manage their worries}

Concerning whom university students ask for support to manage their worries, students' personal features (by themselves) was the most frequent answer (48\%), friends were the second most reported (42\%), family (38\%) and girlfriend/ boyfriend (16\%) were in third and fourth.

Table 2- Current Worries $(\mathrm{N}=50)$ and sources/management of worries $(\mathrm{N}=50)$

\begin{tabular}{|l|r|r|}
\hline & N & \% \\
\hline 1-What are currently your greatest worries? & & 21 \\
\hline University and related matters & 19 & 42 \\
\hline $\begin{array}{l}\text { Time management / Organization of daily } \\
\text { activities }\end{array}$ & 11 & 38 \\
\hline Economic/financial matters & 8 & 22 \\
\hline Family and related matters & 6 & 16 \\
\hline Personal issues & & 12 \\
\hline $\begin{array}{l}\text { 2-What makes you feel well or helps } \\
\text { managing your worry? }\end{array}$ & & \\
\hline Physical exercise & 19 & 38 \\
\hline $\begin{array}{l}\text { Listening to music, watching series/movies, } \\
\text { surfing the net }\end{array}$ & 18 & 36 \\
\hline Walking/ Leaving home / Going to the beach & 12 & 24 \\
\hline Eating sweets and / or junk food & 10 & 20 \\
\hline Sleeping /Staying still & 9 & 18 \\
\hline $\begin{array}{l}\text { 3-Whom do you ask for support to manage } \\
\text { your worry? }\end{array}$ & & \\
\hline Personal features (by myself) & & \\
\hline Friends & 24 & 21 \\
\hline Family & 19 & \\
\hline Girlfriend/ Boyfriend & 8 & \\
\hline
\end{tabular}

\section{Factors associated with having worries}

Using a multivariate logistic regression we obtained an adjusted model (Hosmer and Lemeshow $\chi^{2}=7,944(8) p=.439$ ) and the regression equation explained $31 \%$ of the variance (Nagelkerke $\mathrm{R} 2=.312$ ) and $91.8 \%$ of cases that showed having worries. In this model, the condition of «having worries» is explained by the variables gender (women with a 0.5 times greater likelihood of being in this group) [OR 0.48; 95\% CI 0.35-0.67; $\mathrm{p}=0.000$ ], self-regulation, resilience, empathy, problem solving, self-efficacy, cooperation/ communication (those who reported having had less self-regulation, less resilience, less empathy, less capacity for problem solving, less self-efficacy and less capacity for cooperation/ communication with 0.8 to 1.2 times greater likelihood of being in this group] [OR 0.98; 95\% CI 0.98-0.99; $\mathrm{p}=0.007$; OR 1.18; 95\% CI 1.02-1.35; $\mathrm{p}=0.023$;OR 0.83; 95\% CI 0.70-0.98; $\mathrm{p}=0.027$; OR 0.82; 95\% CI 0.70-0.96; 
$\mathrm{p}=0.016 ;$ OR $0.81 ; 95 \%$ CI $0.67-0.98 ; \mathrm{p}=0.033 ;$ OR $0.80 ; 95 \%$ CI $0.65-0.96 ; \mathrm{p}=0.015$; respectively], physical aggression, anxiety, boredom with university (those who reported having done more physical aggression, more anxiety and more boredom with university with a probability 0.5 to 1.2 times higher to be in this group] [OR $0.90 ; 95 \% \mathrm{CI} 0.84-0.98 ; \mathrm{p}=0.010$; OR 1.16; 95\% CI 0.96-1.13; p=0.000; OR 0.46; 95\% CI 0.31-0.70; $\mathrm{p}=0.000]$, academic performance (those who reported less academic performance, with a probability 1.5 times higher to be in this group) [OR 1.49; 95\% CI 1.06-2.11; $\mathrm{p}=0.023$ ] and relationship with friends (those who reported worse relation with friends, with a probability 1.1 times higher to be in this group) [OR 1.10; 95\% CI 1.00-1.21; $\mathrm{p}=0.043]$.

Table 3 -Factors associated with having worries in Portuguese university students $(\mathrm{N}=\mathbf{2 9 9 1 )}$

\begin{tabular}{lccccc}
\hline & $\boldsymbol{\beta}$ & $\mathbf{S E}$ & $\mathbf{O R}$ & $\mathbf{9 5 \%} \mathbf{I C}$ & $\mathbf{p}$ \\
\hline Gender & -.718 & .165 & 0.488 & $(0.353-0.674)$ & .000 \\
Happiness & .022 & .202 & 1.022 & $(0.688-1.517)$ & .915 \\
Satisfaction with Life & -.065 & .054 & 0.938 & $(0.844-1.042)$ & .231 \\
Self-regulation & -.014 & .005 & 0.986 & $(0.976-0.996)$ & .007 \\
Resilience - Total scale & .161 & .071 & 1.175 & $(1.022-1.350)$ & .023 \\
Empathy - Resilience subscale & -.191 & .086 & 0.826 & $(0.697-0.978)$ & .027 \\
Problem-solving - Resilience subscale & -.198 & .082 & 0.820 & $(0.699-0.963)$ & .016 \\
Self-efficacy - Resilience subscale & -.213 & .100 & 0.808 & $(0.665-0.982)$ & .033 \\
Cooperation/ communication - & -.236 & .097 & 0.790 & $(0.653-0.956)$ & .015 \\
Resilience subscale & -.056 & .124 & 0.945 & $(0.741-1.206)$ & .652 \\
Self-awareness - Resilience subscale & -.009 & .033 & 0.991 & $(0.929-1.058)$ & .790 \\
Buss \& Perry/Aggression - Total scale & .033 & .040 & 1.034 & $(0.956-1.117)$ & .403 \\
Hostility - Aggression subscale & & & & \\
Physical aggression- Aggression & -.102 & .040 & 0.903 & $(0.836-0.976)$ & .010 \\
subscale & .040 & .043 & 1.041 & $(0.958-1.132)$ & .344 \\
Wrath- Aggression subscale & .152 & .013 & 1.164 & $(0.958-1.132)$ & .000 \\
Stai trait - anxiety scale & .773 & .209 & 0.462 & $(0.306-0.696)$ & .000 \\
Boredom with University & .402 & .177 & 1.495 & $(1.057-2.114)$ & .023 \\
Academic performance & .054 & .043 & 1.056 & $(0.971-1.148)$ & .201 \\
Relationship with family & .099 & .049 & 1.104 & $(1.003-1.214)$ & .043 \\
Relationship with friends & &
\end{tabular}

OR: adjusted odds ratios for all variables in the table; CI: confidence interval

\section{LIMITATIONS AND STRENGTHS}

The present results need to be interpreted keeping in mind: recall bias might be introduced through self-report, and some youths may be under-represented, due to the group's heterogeneity; the cross-sectional design of the study precludes inferences concerning causality and longitudinal data would be needed.

However, the present study has numerous strengths, namely including self-reports from a large sample of youths, the use of well-developmentally appropriate measures, and it is based on an international project, namely the Health Behaviour in School-aged Children (HBSC/WHO) international survey. In addition, it brings novelty bringing data to increase the understanding the main worries in the Portuguese university students and their interaction with relevant psychosocial variables for the promotion of mental health.

\section{DISCUSSION}

Overall, most university students reported being satisfied and happy with their lives. Nevertheless, about $9 \%$ and $19 \%$ of all students reported being worried several times a day or worried almost every day and $12 \%$ reported worries so intense that they significantly 
interfered with their daily lives, not allowing them to think or do anything else. As for selfregulation and resilience regarding worries prevention, in general most students have good levels. Nevertheless, two resilience subscales presented slightly lower mean values, namely the problem-solving subscale and the cooperation / communication scale.

As for gender differences, female students reported worrying more frequently and feeling worries in a more intense way than men. In addition, they reported more emotion-focused strategies than men, which is in line with other studies [6,25,26], thus suggesting that a special attention should be dedicated to women.

Students in Portugal are worrying to such an extent that it is affecting their mental health. According to these findings, more than a third of students say that university and related matters and time management / organization of daily activities, and more than a fifth of students say that financial worries have an impact on their mental health.

Moreover, the results of this study suggest that university students' worries can be categorized into five personal domains: worries about university life conditions (academic performance, and future expectations and life professional success), time management / organization of daily activities (academic, domestic and leisure activities such as practising sports, dancing/music and having no free time), economic/financial conditions (lack of money, parental unemployment, parental migration and extreme deprivation), family conditions (like diseases and deaths) and personal issues (unwellness and potentially health compromising behaviours). These results are consistent with previous research findings that students' worries can be placed into categories of worries about the self and not about the state of society[6,7,27].

Regarding to what really makes them feel well or help them manage their worries, university students reported physical exercise (38\%), listening to music, watching series/movies, surfing the net (36\%), walking/ leaving home / going to the beach (24\%), eating sweets and/or junk food (20\%) and sleeping/staying still (18\%). And, when asked whom to turn to for help, the students mentioned no one as a first choice (they try to overcome their worries by themselves, $48 \%)$, followed by friends (42\%), family (38\%) and girlfriend/ boyfriend (16\%). The university was considered a worry but it was not presented as a solution or a resource to deal with life worries.

In accordance with our results and literature, university and academic success are part of young people worries, but never pointed out as a part of the solution. In fact, e.g. the tests (as a way to measure academic success) are a source of worry and even anxiety for students and that anxiety is a cause of academic failure ${ }^{28,29]}$ leading to a seemingly endless cycle. Sometimes worries are apprehended as so intense that they even prevent students from thinking and acting, thus it is quite troublesome to understand that university cannot find its way in helping students dealing with life worries, solving daily life problems (university matters included) or even offering some guidance or support on how to manage and overcome worries. Furthermore, poor academic achievement may be a risk factor for the development of problematic behaviours leading to a poorer self-rated health[30]. With these aspects in mind, it would be positive if coping strategies and positive development were covered in university.

Economic/financial concerns were the third most frequent worry stated. This study showed that university students are even more worried about "money matters" than other youth. They mentioned lack of money, parental unemployment, parental migration and extreme deprivation [24] (Reis, Matos, Aventura Social, 2017). In previous studies conducted with 
adolescents by Aventura Social team in 2010 and 2014 [6,7], just before the beginning of the economic recession in Portugal, one of the most salient issues and sources of worries was economic and financial problems, suggesting that adolescents were already concerned and sensitive to socio economic issues, thus confirming our results.

In our model, the condition of «having worries» is associated to being woman, having less selfregulation, less resilience, less empathy, less capacity for problem solving, less self-efficacy, less cooperation/ communication, more physical aggression, more anxiety, more boredom with university, less academic performance and worse relationship with friends. This condition demonstrated to be relevant and negatively associated with young people's perception of wellbeing, self-regulation and resilience; showing that the mental health of the Portuguese university students is at risk, with a gap in their social emotional skills.

According the statistics, at any given time, approximately $25 \%$ of the general population experience some mental health issues ${ }^{[31]}$. Recent research indicates also that the numbers are much higher for people enrolled in Higher Education than for the general population ${ }^{[32]}$.

The number of university students struggling with mental-health problems is increasing in Europe, according to counsellors and researchers, and their symptoms are getting more severe ${ }^{[33]}$. Suicide is the second-leading cause of death among university students, but it is relatively rare and the reasons behind it are complex [34]. In many ways, universities are the perfect incubators for mental-health problems. Illnesses such as depression and anxiety often strike in late teens and early twenties, and students, often far from family, face common triggers: break-ups, drug use, the pressure to have good grades while expenses pile up[33].

\section{IMPLICATIONS}

This research on worries should contribute both to demonstrate that developing adaptive strategies is a fundamental capability as a tool to find solutions related to one's worries and as a competence to be developed throughout the different stages of human life as it helps in the promotion of well-being and interacts positively in quality of life. Overall, the findings reinforce the need to continue to study positive indicators, and to strengthen internal and external developmental assets ${ }^{[1,35]}$, as literature suggests ${ }^{[6,7,30]}$. These results are also in line with more recent health recommendations, namely the need to include psychosocial factors in complement to health indicators ${ }^{[3]}$. And the results also support the claim that to increase the knowledge in this area can help young people, their families, health professionals, educators, and policy-makers to improve effectiveness in interventions/policies and promoting an integral healthy perspective for youths, relying on interdisciplinary and transdisciplinary work. Focusing on youths' assets and on creative ways to foster their social active engagement as citizens seems a relevant, necessary and urgent action, especially in the present sociohistorical and political-cultural situation where new challenges occur in a daily basis, and where facing such quick changes using positives approaches may help turning difficulties into opportunities.

Altogether, it is expected that such findings can help researchers, educators and practitioners to increase the knowledge of the students' worries and their interaction between the study of psychosocial variables. Moreover, they may be a guidance to plan youth interventions focused on the construction of a supportive context in order to decrease their anxiety, and to improve their competences of self-regulation, resilience, and perceived school performance. Human beings are born with an instinctive capacity for self-regulation and resilience, and that results when they respond to risk with properly functioning adaptation systems. The capacity to cope with risk successfully changes over time (particularly in young people who are experiencing 
developmental changes), and is enhanced by protective and promotive factors within the environment and the person, which means that coping strategies are enhanced throughout time, thus potentially becoming adaptive.

As long as the balance between risks and protective factors is manageable, people are able to adapt and cope adequately. To ensure the likelihood of positive adaptation, counteracting factors must be strengthened at the individual, family, and community levels. Therefore, exposure to moderate stressors, challenges, and risks can help children and young people to develop adaptive coping responses and resilience.

Today's children are growing up in an increasingly stressful world. As everyone faces stress at some point, it is unrealistic to think that children can be shielded completely from experiencing stress and worries. Children and youth are more resilient when they live in safe and stable environments; have strong connections to families, schools, and communities; and are able to develop age-appropriate cognitive and social skills.

Early exposure to multiple risk factors increases the likelihood of adverse effects on healthy development; and the negative impact increases over time. Therefore, it is important to promote resilience in children as early as possible by implementing the most effective interventions within the context of the child, family, school, and broader community.

Additionally, young people's perception about their lives, their worries and their assets is a relevant health issue and should be given a special focus in mental health and well-being promotion programs in university settings, with a very special focus on females.

University success and future positive expectations are relevant issues related to young people's mental health and well-being. Universities should promote resilience and emotional literacy (i.e. the ability to be aware and express in an appropriate way one's emotions so as to be able to regulate one's mental states) as a relevant part of mental health and its well-being programs, while simultaneously helping students to achieve success, and maintaining positive expectations towards their future. In this context, health education and health promotion at universities gains renewed relevance.

However, what concerns interventions, it is highlighted that positive youth development is just an approach and not a particular curriculum or program, meaning that it can be additionally included in other programs designed to achieve, more likely, one or more positive outcomes [36] towards an optimistic life plan, and an attainable happy and healthy life [6]. It is crucial to remember that youths are the most important assets in society and it is important to continue the study on the identification of indicators for positive youth development because once it occurs, it can empower not only youths, but also families, communities and societies, with potential benefits for the next generations. Accordingly, investments in youths can signify a highly cost-effective opportunity towards future positive changes $[6,37]$.

\section{FUNDING}

Foundation for Science and Technology (FCT) (Grants: Marta Reis -SFRH/BPD/110905/2015)

\section{ACKNOWLEDGEMENTS}

A special thanks to Aventura Social team and to all the universities, students, teachers and experts who participated in this study. To the HBSC/ WHO network (www.hbsc.org) whose survey was partially used for this purpose. 


\section{References}

1. Williams, A. S. (2013). Worry, intolerance of uncertainty, and statistics anxiety. Statistics Education Research Journal, 12, 48-59. [Online: www.stat.auckland.ac.nz/serj]

2. American Psychiatric Association, DSM-5 Task Force. (2013). Diagnostic and statistical manual of mental disorders: DSM- $5^{\mathrm{TM}}$ (5th ed.). Arlington, VA, US: American Psychiatric Publishing, Inc.. http://dx.doi.org/10.1176/appi.books.9780890425596

3. Stokes, C., \& Hirsch, C. R. (2010). Engaging in imagery versus verbal processing of worry: Impact on negative intrusions in high worriers. Behaviour research and therapy, 48(5), 418-23.

4. Hallion, L. S., Ruscio, M. A., \& Jha, A. P. (2014). Fractionating the role of executive control in control over worry: a preliminary investigation. Behavior Therapy and Research, 54, 1-6.

5. Hirsch, C. R., Mathews, A., Lequerier, B, Perman, G. \& Hayes, S. (2013). Characteristics of worry in Generalized Anxiety Disorder. Journal of Behavior Therapy and Experimental Psychiatry, 44, 388-395.

6. Matos, M.G., Reis, M., Ramiro, L., Camacho, I., Tomé, G., Branquinho, C. (2018) The Role of Worries in Mental Health and Well-Being in Adolescence in Portugal. In: Pashang S., Khanlou N., Clarke J. (eds) Today's Youth and Mental Health. Advances in Mental Health and Addiction. Springer, Cham. https://doi.org/10.1007/978-3-319-64838-5_9

7. Matos, M.G., Sampaio, D., Baptista, I., \& Equipa Aventura Social, UTL and CMDT/UNL (2013). Adolescent's health education and promotion in Portugal: a case study of sustainable practice. In Samdal, O., \& Rowling, L. (Eds.) , The Implementation of health promoting schools, exploring the theories of what, why and how (pp123-126). New York: Routledge Taylor \& Francis Group.

8. Brown, S., Teufel, J., Birch, D., \& Kancherla, V. (2006). Gender, age and behavior differences in early adolescence worry. Journal of School Health, 76(8), 430-437.

9. Robinson, O. J., Vytal, K., Cornwell, B. R., \& Grillon, C. (2013). The impact of anxiety upon cognition: perspectives from human threat of shock studies. Frontiers in human neuroscience, 7, 203. doi:10.3389/fnhum.2013.00203

10. Benedetto, L., Di Blasi, D., \& Pacicca, P. (2013). Worry and Meta-Cognitive beliefs in Childhood Anxiety Disorders. Mediterranean Journal of Clinical Psychology, 1(3), 1-14. Doi: 10.6092/2282-1619/2013.1.932

11. Matos, M. G., Gaspar, T., Tomé, G., \& Cruz, J. (2012). Worries and well-being during childhood and adolescence. Pakistan Journal of Clinical Psychology, 11(1), 3-14.

12. Gaspar, T., Matos, M. G., Foguet, J., Ribeiro, J. L., \& Leal, I. (2010). Parent-child perceptions of quality of life: Implications for health intervention. Journal of Family Studies, 16(2), 143-154.

13. Gaspar, T., Matos, M. G., Ribeiro, J., Leal, I., \& Ferreira, A. (2009). Health-related quality of life in children and adolescents and associated factors. Journal of Cognitive and Behavioral Psychotherapies, 9(1), 33-48.

14. Simões, C., Matos, M. G., Tomé, G., \& Ferreira, M. (2009). Ultrapassar adversidades e vencer os desafios (Overcoming adversities and winning challenges; manual for promoting resilience for parents and professionals). Lisboa: Aventura Social e Saúde/Faculdade de Motricidade Humana.

15. Constantine, N.A., \& Benard, B. (2001). California Healthy Kids Survey Resilience Assessment Module: Technical Report. Berkeley, CA: Public Health Institute.

16. Martins, M. H. (2007). Resiliência: para além da diversidade e do risco. [Resilience: beyond diversity and risk].Actas do II Congresso Família, Saúde e Doença, Modelos, Investigação e Prática em diversos contextos de Saúde. Universidade do Minho: Braga.

17. Simões, C., Matos, M.G., \& Morgan, A. (2015). Facing the adversity: The role of internal assets on wellbeing in adolescents with special needs. Spanish Journal of Psychology, 18(e56), 1-14. https://doi.org/10.1017/sjp.2015.41

18. Dias, P., Castillo, J.A., \& Moilanen, K. (2014). The Adolescent Self-Regulatory Inventory (ASRI) Adaptation to Portuguese Context. Paidéia, 24(58), 155.163. https://doi.org/10.1590/1982-43272458201403

19. Moilanen, K. L. (2007). The Adolescent Self-Regulatory Inventory: The development and validation of a questionnaire of short-term and long-term self-regulation. Journal of Youth and Adolescence, 36, 835848. https://doi.org/10.1007/s10964-006-9107-9

20. Silva, D., \& Spielberger, C. D. (2007). Manual do Inventario de Estado-Traço de Ansiedade (STAI), [Manual for the State-Trait Anxiety Inventory]. Consulting Psychologists Press, Inc. 
21. Spielberger, C., Gorsuch, R., \& Lushene, R. (1970). Manual for state-trait Anxiety Inventory. Palo Alto, CA: Consulting Psychologists Press.

22. Simões, A. (1993). São os homens mais agressivos que as mulheres? Revista Portuguesa de Pedagogia, XXVII(3), 387-404.

23. Cunha, O., \& Gonçalves, R. (2012). Análise confirmatória fatorial de uma versão portuguesa do Questionário de Agressividade de Buss-Perry. Laboratório de Psicologia, 10(1), 3-17.

24. Reis, M, Matos, M.G., \& Aventura Social (2017). Comportamentos de saúde dos jovens universitários Portugueses - Relatório do estudo / Dados Nacionais de 2016. Aventura Social/FMH/Ulisboa. http://aventurasocial.com/arquivo/1499021788 JUNP Relatorio junho2017 v8F 28junho2017.pdf

25. Bahrami, F., \& Yousefi, N. (2011). Females are more anxious than males: a metacognitive perspective. Iranian journal of psychiatry and behavioral sciences, 5(2), 83-90.

26. El-Shormilisy, N., Strong, J Meredith, P. J. (2015). Associations between gender, coping patterns and functioning for individuals with chronic pain: a systematic review. Pain research \& management, 20(1), 48-55.

27. Kelly, W. E. (2007). The structure of adult students' worries. Educational Research Quarterly, 31(1), 17-26.

28. Hassanzadeh, R., Ebrahimi, S., \& Mahdinejad, G. (2012). Studying Test Anxiety and Its Relationship with Self-Efficacy, Metacognitive Beliefs and Some Effective Predictable Variables. European Journal of Social Sciences, 30(4), 511-522.

29. Valiente, C., Swanson, J., \& Eisenberg, N. (2012). Linking Students' Emotions and Academic Achievement: When and Why Emotions Matter. Child development perspectives, 6(2), 129-135.

30. Malinauskienea, O., Vosylisa, R., \& Zukauskiene, R. (2011). Longitudinal examination of relationships between problem behaviors and academic achievement in young adolescents. Procedia Social and Behavioral Sciences, 15, 3415-3421.

31. NIMH - National Institute of Mental Health (2018). Mental Health Staistics. Retrived from https://www.nimh.nih.gov/health/statistics/mental-illness.shtml\#part 154910

32. Analysis of Higher Education Statistics Authority, (2017). 'Who's Studying in HE?', https://www.mentalhealth.org.uk/publications/how-manage-and-reduce-stress

33. Mental Health Foundation (2018). Stress: Are we coping? London: Mental Health Foundation.

34. Office for National Statistics (2017). Suicides in the UK. Available at: https://www.ons.gov.uk/peoplepopulationandcommunity/birthsdeathsandmarri.

35. Hirsch, C. R., \& Mathews, A. (2012). A cognitive model of pathological worry. Behaviour research and therapy, 50(10), 636-46.

36. Moore, K. (2017). Commentary: Positive Youth Development Goes Mainstream. Child Development, Special Section is Positive Youth Development in Diverse and Global Contexts, 88(4), 1175-1177. doi: 10.1111/cdev.12874

37. Petersen, A., Koller, S., Motti-Stefanidi, F., \& Verma, S. (2017). Positive youth development in global contexts of social and economic change. Abington, UK: Taylor \& Francis Group. 